\title{
Can Near-Peer Teaching Improve Academic Performance?
}

\author{
Brett Williams ${ }^{1} \&$ James Fowler ${ }^{2}$ \\ ${ }^{1}$ Head of Department, PhD., Department of Community Emergency Health and Paramedic Practice, Monash \\ University, Australia \\ ${ }^{2}$ Research Assistant, BN/BEH(candidate), Department of Community Emergency Health and Paramedic Practice, \\ Monash University, Australia \\ Correspondence: Brett Williams, Assoc Professor, Department of Community Emergency Health \& Paramedic \\ Practice, Monash University -Peninsula Campus, PO Box 527, McMahons Road, Frankston, Victoria, Australia, \\ 3199. Tel: 61-3-9904-4283 Fax: 61-3-9904-4168 E-mail: brett.williams@monash.edu
}

Received: September 26, 2014

Accepted: October 24, 2014

Online Published: October 27, 2014

doi:10.5430/ijhe.v3n4p142

URL: http://dx.doi.org/10.5430/ijhe.v3n4p142

\begin{abstract}
Near peer teaching is becoming increasingly popular within healthcare education. The experiences and effects of near-peer teaching upon the near-peer teachers' academic performance are poorly understood. In order to address this, the objective of this study was to examine whether a near-peer teaching program improved the overall clinical unit scores of undergraduate paramedic near-peer teachers.

Students in their final year of an undergraduate paramedic, or nursing/paramedic degree were given the opportunity to volunteer as near-peer teachers for a first year clinical skills unit. The overall unit scores in a final year clinical unit of 74 students involved in the near-peer teaching program were compared with a randomly selected sample not involved.

74 students participated in this study as near-peer teachers between 2011-2013 ( $\mathrm{n}=23$ in 2011, $\mathrm{n}=18$ in 2012, $\mathrm{n}=33$ in 2013). In each year, the median clinical unit grade of participating near-peer teachers was significantly higher than that of the students not involved in the near-peer teaching program when examined using a Mann-Whitney $U$ Test ( 71 vs $67, p=0.006$ in $2011 ; 76$ vs $72, p=0.007$ in $2012 ; 75$ vs $71, p=0.004$ in 2013). This study has demonstrated that participation in a near-peer teaching program can result in improved overall clinical unit grades for undergraduate paramedic near-peer teachers. This study has added objective data to the variety of subjective information evaluating the effects of near-peer teaching upon the teachers themselves.
\end{abstract}

Keywords: Nurse, Paramedic, Peer teaching, Near-peer teaching

\section{Introduction}

Although its precise origins remain unclear, peer teaching has existed in some form since ancient Greece (Secomb, 2008; Youdas, Hoffarth, Kohlwey, Kramer, \& Petro, 2008) Peer teaching has since been introduced in primary and secondary education from the 1960's, and now forms part of many tertiary health care courses (Best, Hajzler, Ivanov, \& Limon, 2008; Evans \& Cuffe, 2009; Ten Cate \& Durning, 2007a) It has long been accepted that teaching others is of benefit to the teachers themselves, whether that be through the acquisition of knowledge or teaching ability (Iwata, Furmedge, Sturrock, \& Gill, 2014).

In its simplest form, peer teaching can be defined as the process of helping fellow students to gain knowledge, understanding, or skills in a way that is typically of benefit to both parties (McKenna \& French, 2011; Silbert, Lam, Henderson, \& Lake, 2013). This can range in formality, from peers explaining difficult concepts to one another to peer teaching forming a compulsory part of the educational curriculum (McKenna \& French, 2011; Ten Cate \& Durning, 2007a). Throughout its evolution, peer teaching has been known by a number of terms including: peer-assisted learning (PAL), team-based learning, peer tutoring, education through student interaction (ETSI), and peer mentoring (Evans \& Cuffe, 2009; Lockspeiser, O'Sullivan, Teherani, \& Muller, 2008; Ten Cate \& Durning, 2007a). The term "near-peer teaching" was introduced by Whitman (1988), and refers to students one or more years senior in the same, or similar discipline teaching junior students. This term has been widely adopted in the literature, and henceforth this paper will use the term 'near-peer teacher'to refer to peer teachers one or more years advanced in their studies than the learners they are educating (Ten Cate, van de Vorst, \& van den Broek, 2012). The impact of 
near-peer teaching upon student learners across a range of healthcare disciplines has been well documented. In a retrospective analysis of 36 medical courses Ten Cate et al. (2012) found that students taught by near-peers outperformed their faculty-taught colleagues in 29 of those courses. Similarly, in a randomised controlled trial by Hughes et al. (2010), near-peer taught medical students had equal pass rates to their expert-taught peers in an advanced resuscitation objective structured clinical examination (OSCE) following a seven week course. Similar results have also been obtained with students from other healthcare disciplines, with Perkins et al. (2002) determining that dental, medical, nursing, and physiotherapy students were significantly more likely to pass a practical CPR examination when taught by near-peers than when taught by experienced clinical staff.

However, the experiences and effects of near-peer teaching upon the academic performance of near-peer teachers themselves are much less clearly understood. Much of the available literature is descriptive in nature, and there is a distinct paucity of papers empirically evaluating what, if any, impact near-peer teaching has upon the knowledge and skill acquisition of near-peer teachers. Subjective analyses have revealed possible benefits of increases in motivation, confidence, reflective practice, communication skills, deeper learning, as well as teaching and feedback ability (Evans \& Cuffe, 2009; McKenna \& French, 2011; Nelson et al., The role of paramedics within Australia has undergone dramatic change within recent decades (O'Meara, 2009; Williams, Onsman, \& Brown, 2009, 2012). There has been a shift in focus from protocol-driven 'treat and transport', towards 'assess, treat, and refer appropriately'guided by autonomous judgement and clinical reasoning (O'Meara, 2009; Williams et al., 2009, 2012). Alongside these changes is an increased requirement to educate patients regarding treatment plans and other healthcare practitioners as they develop skills and knowledge. This belief appears to be shared by the current paramedic workforce, with an analysis by Williams et al. (2012) finding that 'leadership and mentoring'was viewed as an important graduate attribute amongst 872 practicing paramedics. Similarly, a significant proportion of the 78 paramedic students who participated McLelland et al.'s (2013) inter-professional near-peer teaching study responded positively to the statement that "teaching is an important role for paramedics." Furthermore, both of the peak bodies for paramedic practice within Australia: Paramedics Australasia (2011) and the Council of Ambulance Authorities (2010), list "Participates in the mentoring, teaching, and development of others"as a key competency.

Despite this, there are currently no formal standalone units in teaching methods or pedagogical theory within the Australian paramedic curricula nationally. The majority of undergraduate paramedic degrees in Australia are now nationally accredited. As described in the literature review below, there is a distinct lack of data measuring the effects of near-peer teaching upon the teachers themselves. This is particularly evident within undergraduate paramedic education, where only limited and underpowered attempts have been made to evaluate the effects of near-peer teaching. (Best et al., 2008; Williams, Fellows, Eastwood, Wallis, \& McKenna, 2013 (in press)).

Therefore, in order to address the limited objective data regarding the impact of near-peer teaching upon academic performance, the objective of this study was to examine whether a near-peer teaching program improved the overall clinical unit scores of undergraduate paramedic near-peer teachers.

\section{Literature Review}

The prevalence of near-peer teaching within healthcare education is increasing, and hence there has also been an increase in associated literature. There have been numerous studies evaluating perceptions and effects of near-peer teaching upon the learners, some of which are outlined below. Conversely, it appears as if there is a relative paucity in studies evaluating the effects of near-peer teaching upon the teachers themselves.

In a retrospective analysis of 36 medical courses Ten Cate et al. (2012) found that students taught by near-peers outperformed their faculty-taught colleagues in 29 of those courses. Similarly, in a randomised controlled trial by Hughes et al. (2010), near-peer taught medical students had equal pass rates to their expert-taught peers in an advanced resuscitation objective structured clinical examination (OSCE) following a seven week course. Similar results have also been obtained with students from other healthcare disciplines, with Perkins et al. (2002) determining that dental, medical, nursing, and physiotherapy students were significantly more likely to pass a practical CPR examination when taught by near-peers than when taught by experienced clinical staff.

Through a series of evaluative reviews, near-peer learners have reported numerous benefits of near-peer teaching. Near-peer learners have identified near-peer teachers as more approachable, and better able to create a relaxed atmosphere for raising concerns or difficulties (McLelland et al., 2013; Ten Cate \& Durning, 2007a, 2007b). The concept of cognitive congruence describes the reduced distance in academic knowledge and cognitive development between near-peer teachers and learners (Lockspeiser et al., 2008; Ten Cate \& Durning, 2007a, 2007b; Yu et al., 2011). As a result of this, learners report that near-peers are better able to understand the learning needs of students, and hence target information at an appropriate knowledge level (Lockspeiser et al., 2008; Rashid, Sobowale, \& Gore, 
2011; Ten Cate et al., 2012). Lockspeiser et al. (2008) empirically validated this theory using focus groups and surveys of 111 first year medical students who were taught by second year near-peers. In this study, learners reported that near-peer teachers were better able to predict, and subsequently explain methods to overcome difficult concepts, suggesting they understood the learner's level of knowledge; a key aspect of cognitive congruence (Lockspeiser et al., 2008). Additional benefits of increased learner motivation, confidence, emotional support, and acquisition of the 'unwritten rules'to get through the course of study have also been reported (McKenna \& French, 2011; Secomb, 2008; Ten Cate \& Durning, 2007a; Yu et al., 2011). Near-peer teaching is also viewed by learners as a preferred method of teaching, with McLelland et al. (2013) finding that $76.9 \%$ of 78 participating undergraduate paramedic students enjoyed interacting with midwifery students in an inter-professional near-peer teaching program in Australia. Similarly, almost all learners who participated in a peer mentoring program in paramedic studies at an Australian university perceived the program as a positive experience, with both social and cognitive benefits highlighted (Best et al., 2008).

However, the experiences and effects of near-peer teaching upon the academic performance of near-peer teachers themselves are much less clearly understood. Much of the available literature is descriptive in nature, and there is a distinct paucity of papers empirically evaluating what, if any, impact near-peer teaching has upon the knowledge and skill acquisition of near-peer teachers.

In one of only few studies to do so within paramedic education, Williams et al. (2013 (in press)) describe a pilot study that later evolved into the near-peer teaching program featured in this study. However, the primary focus was upon the subjective experiences of near-peer teachers rather than empirical impacts upon final grade scores, and only two years of data was available (Williams et al., 2013 (in press)). Nonetheless, as a comparison finding it was reported that those participating in near-peer teaching achieved statistically significantly higher final clinical exam scores $(76.5 \%$ vs. $71.0 \%$ : p $<0.0001$, and $75.2 \%$ vs. $72.7 \%$ : p $<0.0001)$ (Williams et al., 2013 (in press)). While Williams et al.'s (2013 (in press)) study used single exam scores to examine the effects of near-peer teaching, this study facilitated a more thorough examination by comparing final grade scores for the entire clinical unit.

The efficacy of near-peer teaching at increasing the teacher's knowledge acquisition and retention has been established within the areas of medical and physiotherapy education (Peets et al., 2009; Youdas et al., 2008). Peets et al. (2009) randomly allocated 135 medical students specific topics to teach their peers within a gastroeneterology/haematology course, and subsequently found that students outperformed their colleagues in exam questions regarding the topic they acted as peer teachers for (mean score $80.7 \%$ vs $77.6 \%, \mathrm{p}<0.01$ ). In a smaller study, Youdas et al. (2008) found that of four physiotherapy students involved in near-peer teaching of anatomy, three achieved above the class mean in a final anatomy exam. As these results were obtained following studies on semi-cognate professions, caution should be taken before extrapolating findings to the field of paramedic education.

Conversely, in a study of similar design to this one, Iwata et al. (2014) found that near-peer teaching did not result in significant improvements to academic performance amongst medical students after accounting for possible self-selection bias. However, Iwata et al.'s (2014) volunteer near-peer teachers demonstrated significantly greater academic aptitude than their colleagues prior to commencing the program. Despite showing that near-peer teaching significantly improved results in three different types of final year medical school exams from 2010-2012 $(\mathrm{p}=0.001-\mathrm{p}=0.009)$, when using year 4 examination results as a co-variate in ANCOVA, any improvements to academic performance were no longer significant $(\mathrm{p}=0.090-\mathrm{p}=0.851)$ (Iwata et al., 2014). Iwata et al. (2014) present an innovative approach to retrospectively addressing the possible self-selection bias that could be reproduced in future studies. However, once again, caution must be taken before extending these results to paramedic education.

\section{Methods}

Design:

A comparative research design was used to compare the clinical unit grades of near-peer teachers with colleagues not involved in near-peer teaching over a three year period from 2011 to 2013.

\section{Participants:}

Students in their final year of the Bachelor of Emergency Health (BEH) at Monash University were given the opportunity to volunteer as near-peer teachers during practical classes of a first year clinical skills unit. Inclusion criteria were current enrolment in final year of the $\mathrm{BEH}$, and willingness to voluntarily participate in the near-peer teaching program for at least five sessions. There were no exclusion criteria and no maximum number of available near-peer teacher positions, and hence it was not possible to prospectively control the sample size. Potential participants were advised of the near-peer teaching program through printed posters and short in-class information 
sessions by academic staff. The BEH program is a three year pre-employment (pre-registration) degree offered to students seeking to practice as a paramedic within an emergency ambulance service. The BEH program does not include any formal education or assessment of students'ability to teach others. Prior to commencing the near-peer teaching program, some near-peer teachers were provided with a short session explaining the aims of near-peer teaching, learning outcomes, and various teaching methodologies. The near-peer teaching program ran for the full duration of the 12 week academic semester. Each near-peer teaching session was formative in nature and did not involve any assessment or summative grading for near-peer learners.

\section{Procedures:}

During the near-peer teaching sessions, up to two near-peer teachers were placed in a class of approximately 12 first year students and one paid sessional university staff member during a practical and/or simulation class. The near-peer teachers worked alongside faculty staff to provide feedback, contribute to realistic case simulations, and share experiences and practical knowledge with first year students. Near-peers teachers allocated themselves to first year classes using an online class timetabling spreadsheet, which was subsequently shared with all sessional university staff. Detailed lesson plans, learning objectives, and anticipated learner difficulties were made available to near-peer teachers prior to their allocated near-peer teaching session.

Across three years the grades of the penultimate final clinical unit were compared between those involved in the near-peer teaching program and a random selection of students not involved in the program. To explore the accidental possibility of a self-selection bias, the examination scores between these two cohorts were also compared in two clinical subjects prior to commencing the near-peer teaching program in their final year a first year unit titled 'Clinical Concepts of Paramedic Practice', and a second year unit titled 'Paramedic Management of Cardiac and Respiratory Conditions'.

A short self-report survey was also distributed to participants prior to commencing the near-peer teaching program, and responses to the question 'do you think this peer teaching project will help you to achieve better grades in your paramedic clinical units?' were examined as additional comparison findings.

Instrumentation:

Across three years, the overall unit scores in a final year BEH clinical unit of 74 students involved in the near-peer teaching program were compared with a randomly selected 74 students not involved in the program. Clinical unit results were collected over a three year period.

\section{Statistical Analyses:}

Quantitative data was analysed using Statistical Package for the Social Sciences (SPSS, SPSS Inc., Chicago), investigating differences in median scores and interquartile ranges for the final year unit clinical unit scores. Demographic data were summarised by percentage. A Mann-Whitney $U$ Test was performed to compare for differences in scores between those involved in near-peer teaching, and those not involved. Results were considered statistically significant if the $\mathrm{p}$ value was $<0.05$.

Ethics:

Ethics approval was granted by the Monash University Human Research Ethics Committee. Participants were provided with an explanatory statement and advised that their participation was voluntary. Participating students were able to withdraw from the near-peer teaching program at any time without penalty. The near-peer teaching program was overseen by academic staff for its full duration to ensure ethical conduct. Participant data was anonymised, and hence no names were associated with clinical unit scores or survey responses.

\section{Results}

\section{Participant Demographics:}

A total of $\mathrm{n}=74$ students participated in this study between 2011-2013: ( $\mathrm{n}=23$ in 2011, $\mathrm{n}=18$ in 2012, $\mathrm{n}=33$ in 2013). The majority of near-peer teachers were female (68.9\%) and under the age of $26(72.9 \%)$ (see Table 1$)$. 
Table 1. Participant Demographics

\begin{tabular}{llllllllll}
\hline & & 2011 & & 2012 & & 2013 & \multicolumn{3}{c}{ All } \\
& & $\mathrm{n}$ & $\%$ & $\mathrm{n}$ & $\%$ & $\mathrm{n}$ & $\%$ & $\mathrm{n}$ & $\%$ \\
\hline Age & $<21 \mathrm{yrs}$ & 15 & 65.2 & 4 & 21.1 & 17 & 53.1 & 36 & 48.6 \\
& $22-25 \mathrm{yrs}$ & 3 & 13 & 9 & 47.4 & 6 & 18.8 & 18 & 24.3 \\
& $26-30 \mathrm{yrs}$ & 2 & 8.7 & 5 & 26.3 & 0 & 0 & 7 & 9.5 \\
& $31-35 \mathrm{yrs}$ & 2 & 8.7 & 0 & 0 & 8 & 25 & 10 & 13.5 \\
& $>36 \mathrm{yrs}$ & 1 & 4.3 & 1 & 5.3 & 1 & 3.1 & 3 & 4.1 \\
& & & & & & & & & \\
Gender & Female & 15 & 65.2 & 12 & 63.2 & 24 & 75 & 51 & 68.9 \\
& Male & 8 & 34.8 & 7 & 36.8 & 8 & 25 & 23 & 31.1 \\
\hline
\end{tabular}

Comparison of Clinical Unit Overall Scores

The median final year clinical unit scores of near-peer teachers $(2011, n=23 ; 2012, n=18 ; 2013, n=33 ;$ total, $n=74)$ were compared to that of a random selection of students not involved in the near-peer teaching program for each individual year from 2011-2013 (2011, $\mathrm{n}=23 ; 2012, \mathrm{n}=18 ; 2013, \mathrm{n}=33$; total, $\mathrm{n}=74)$. In each year, there was a statistically significant difference between the peer teachers and those not involved in the near-peer teaching program (see Table 2).

Table 2. Final Year Clinical Unit Overall Scores

\begin{tabular}{llll}
\hline & Group & $\begin{array}{l}\text { Final Year Clinical Unit } \\
\text { Score M } d(\mathrm{IQR})\end{array}$ & Sig \\
\hline 2011 & Near-peer teachers $(\mathrm{n}=23)$ & $71(69-80)$ & \\
& Random sample $(\mathrm{n}=23)$ & $67(59-75)$ & $p=0.006$ \\
2012 & Near-peer teachers $(\mathrm{n}=19)$ & $76(72-86)$ & \\
& Random sample $(\mathrm{n}=19)$ & $72(70-78)$ & \\
2013 & Near-peer teachers $(\mathrm{n}=32)$ & $75(73-78)$ & \\
& Random sample $(\mathrm{n}=32)$ & $71(70-83)$ & $P=0.007$ \\
& &
\end{tabular}

In an attempt to explore the extent of the self-selection bias, results in other clinical units were also examined in the same groups for year one (Clinical Concepts of Paramedic Practice), and year two (Paramedic Management of Cardiac and Respiratory conditions). As can be seen in Table 3, any differences in final grade scores between these two groups did not reach statistical significance in any year: $(2011: p=.62-p=.79 ; 2012: p=.53-p=.99 ; 2013$ : $p=.23-p=.43$ ). In many years, the random sample who did not later become involved in near-peer teaching actually outperformed those who did. Whilst this does not exclude a possible self-selection bias, it seems to suggest that participants did not demonstrate any significant natural academic aptitude before participating in the near-peer teaching program.

Table 3. Academic Performance of Participants before Commencing Near-peer Teaching

\begin{tabular}{llllll}
\hline \multirow{2}{*}{2} & Group & $\begin{array}{l}\text { First Year Clinical } \\
\text { Unit Score Md(IQR) }\end{array}$ & Sig & $\begin{array}{l}\text { Second Year Clinical } \\
\text { Unit Score Md (IQR) }\end{array}$ & Sig \\
\hline \multirow{2}{*}{2011} & Near-peer teachers $(\mathrm{n}=23)$ & $75(73-78)$ & $p=0.65$ & $75(66-80)$ & $p=0.62$ \\
& Random sample $(\mathrm{n}=23)$ & $74(71-78)$ & $p=0.67$ & $73(66-78)$ & $p=0.79$ \\
& Near-peer teachers $(\mathrm{n}=19)$ & $74(66-77)$ & $p=0.53$ & $75(70-80)$ & $p=0.99$ \\
& Random sample $(\mathrm{n}=19)$ & $73(67-78)$ & $p=0.37$ & $75(71-80)$ & $p=0.95$ \\
2013 & Near-peer teachers $(\mathrm{n}=32)$ & $74(68-76)$ & $p=0.43$ & $72(66-75)$ & $p=0.42$ \\
& Random sample $(\mathrm{n}=32)$ & $75(71-77)$ & $p=0.23$ & $73(67-75)$ & $p=0.30$ \\
\hline
\end{tabular}


The responses of near-peer teachers to the survey item 'Do you think this peer teaching project will help you to achieve better grades in your paramedic clinical units?' were examined. Possible responses were 'yes' or 'no', and as can be seen in Table 4, the overwhelming majority of responses were positive in every year this study operated (2011, 95.7\%; 2012, 78.9\%; 2013, 100\%).

Table 4. Near-peer Teaching Experience

Do you think this peer teaching project will help you achieve better grades in your paramedic clinical units?

\begin{tabular}{llll} 
& & $\mathrm{n}$ & $\%$ \\
\hline 2011 & Yes & 22 & 95.7 \\
& No & 1 & 4.3 \\
& Yes & 15 & 78.9 \\
2013 & No & 4 & 21.1 \\
& Yes & 32 & 100 \\
& No & 0 & 0 \\
\hline
\end{tabular}

\section{Discussion}

Results from this three year comparative research design study have shown that near-peer teaching improves clinical final grade scores of undergraduate paramedic near-peer teachers, in comparison to colleagues not involved in the near-peer teaching program. These results add unique empirical data to existing knowledge surrounding near-peer teaching in paramedic and healthcare education.

There is growing support for peer teaching programs in undergraduate health care education, and this study provides further positive quantitative evidence for implementation of near-peer teaching programs in paramedic education. Establishing and monitoring near-peer teaching programs requires significant input from academic staff in terms of both effort and time. Therefore, before implementation it is important the efficacy of such programs for both learners and near-peer teachers is established. As mentioned in the literature review, there is already much data examining the effects of near-peer teaching on the learners, with this study now adding to knowledge surrounding possible benefits for the near-peer teachers. Literature is even more limited within paramedic education with Williams et al. (2013 (in press)) describing one of the only studies examining near-peer teaching in this field. This study has added an additional year of data, allowing for more powerful statistical analysis by increasing the sample size to 74 and specifically addressing the possible self-selection bias. In addition, while Williams et al.'s (2013 (in press)) study used single exam scores to examine the effects of near-peer teaching, this study facilitated a more thorough evaluation by comparing final grade scores for the entire unit.

Whilst partially addressed within this study through retrospective analysis, possible self-selection bias remains a significant difficulty when evaluating the effects of near-peer teaching upon the academic performance of the teachers themselves. In attempts to address this, other studies have utilised retrospective repeated measures analysis and novel methodological designs with varying degrees of success (Iwata et al., 2014; Peets et al., 2009). Ideally, participants should be selected so as to ensure those with natural academic aptitude are not over-represented in the near-peer teacher group, however forced participation raises ethical concerns. The best strategy to eliminate a self-selection bias, whilst also upholding the integrity of the near-peer teaching program is yet to be determined.

As well as demonstrating objective improvements to clinical grade scores, this study showed that participants viewed the near-peer teaching program as able to assist in improving their overall grades in clinical units. In all three years of this study, the significant majority of participants responded positively to the question 'Do you think this peer teaching project will help you to achieve better grades in your paramedic clinical units?'(2011, 95.7\%; 2012, 78.9\%; 2013, 100\%). Similar findings have been reported in the fields of nursing, anatomy, physiotherapy, and medical education, with near-peer teachers describing experiences of deeper learning, reinforcement of learned content, and improved organisation and time management skills (Evans \& Cuffe, 2009; Lockspeiser et al., 2008; McKenna \& French, 2011; Youdas et al., 2008). It is an interesting additional finding that the perceived efficacy of the near-peer teaching program appears to match the objectively measured improvements in academic performance.

Future research could further explore any links between the near-peer teacher's perceptions of the program, and any changes in their final grades. The relationship, if any, between the amount of training in educational methodologies provided to the near-peer teachers and changes in unit grades is also poorly understood, and is worthy of further examination. Similarly, in order to determine the most effective near-peer teaching program design, future research 
could assess the effects of teaching session duration, frequency, and class composition upon knowledge and skill acquisition. Near-peer teaching is often perceived as a cost-effective method of education, however no studies evaluating any possible financial advantages could be found, and hence this could be an area for future research.

\section{Limitations}

Although larger than other studies of similar design, this study has a relatively small sample size, with data only collected from one Australian university campus. It is therefore difficult to generalise findings to all undergraduate paramedic students and courses. Even more caution should be taken when generalising conclusions to other health care disciples. Due to the large number of participants across three years, there were variations in the content taught by the near-peer teachers between years. This limited the ability to examine any links between the type of content taught and associated improvements in academic performance. Data were collected over a three year period, and hence the long-term effects of near-peer teaching remain unknown. Participation in the near-peer teaching program was voluntary, and hence there is a possibility of self-selection bias wherein students with more academic aptitude participated in the program. Hence, their clinical unit scores could be expected to be higher than their colleagues with or without participating in the near-peer teaching program. To counteract this, results were also compared in the same groups for clinical units in year one and two, to determine whether participants demonstrated increased academic ability prior to participation in the program. Increased attention to study design and sample selection could allow for prospective methodological minimisation of this self-selection bias.

\section{Conclusion}

This study over three years has demonstrated that participation in a near-peer teaching program can result in improved overall clinical unit grades for undergraduate paramedic near-peer teachers. When compared to colleagues not involved in near-peer teaching, these improvements remained statistically significant for all three years. This study has added objective data to the variety of subjective information evaluating the effects of near-peer teaching upon the teachers themselves within paramedic education. It appears that the teachers also view near-peer teaching as beneficial to improving their final grades. Although more robust methodological design is required to fully eliminate self-selection bias, these positive results add further weight to the mounting argument for implementation of near-peer teaching programs in undergraduate paramedic and health care education.

\section{References}

Best, G., Hajzler, D., Ivanov, T., \& Limon, J. (2008). Peer Mentoring as a Strategy to Improve Paramedic Students' Clinical Skills. Journal of Peer Learning, 1(1), 13-25.

Evans, D. J. R., \& Cuffe, T. (2009). Near-Peer Teaching in Anatomy: An Approach for Deeper Learning. Anatomical Sciences Education, 2(5), 227-233. http://dx.doi.org/10.1002/ase.110

Hughes, T. C., Jiwaji, Z., Lallu, K., Lloyd-Lavery, A., Lota, A., Dale, A., Bulstrode, C. J. (2010). Advanced Cardiac Resuscitation Evaluation (ACRE): A randomised single-blind controlled trial of peer-led vs. expert-led advanced resuscitation training. Scandinavian Journal of Trauma, Resuscitation and Emergency Medicine, 18(1), 3-9. http://dx.doi.org/10.1186/1757-7241-18-3

Iwata, K., Furmedge, D. S., Sturrock, A., \& Gill, D. (2014). Do peer-tutors perform better in examinations? An analysis of medical school final examination results. Medical Education, 48(7), 698-704. http://dx.doi.org/10.1111/medu.12475

Lockspeiser, T. M., O'Sullivan, P., Teherani, A., \& Muller, J. (2008). Understanding the experience of being taught by peers: the value of social and cognitive congruence. Advances in Health Science Education, 13(3), 361-372. http://dx.doi.org/10.1007/s10459-006-9049-8

McKenna, L., \& French, J. (2011). A step ahead: Teaching undergraduate students to be peer teachers. Nurse Education in Practice, 11(2), 141-145. http://dx.doi.org/10.1016/j.nepr.2010.10.003

McLelland, G., McKenna, L., \& French, J. (2013). Crossing professional barriers with peer-assisted learning: Undergraduate midwifery students teaching undergraduate paramedic students. Nurse Education Today, 33(7), 724-728. http://dx.doi.org/10.1016/j.nedt.2012.10.016

O'Meara, P. (2009). Paramedics marching towards professionalism. Journal of Emergency Primary Health Care, 7(1), $1-5$. 
Paramedics Australasia. (2011). Australasian Competency Standards for Paramedics Retrieved from http://www.paramedics.org/content/2011/10/PA_Australasian-Competency-Standards-for-paramedics_July-2011 1.pdf

Peets, A. D., Coderre, S., Wright, B., Jenkins, D., Burak, K., Leskosky, S., \& McLaughlin, K. (2009). Involvement in teaching improves learning in medical students: a randomized cross-over study. BMC Medical Education, 9, 55. http://dx.doi.org/10.1186/1472-6920-9-55

Perkins, G. D., Hulme, J., \& Bion, J. F. (2002). Peer-led resuscitation training for healthcare students: a randomised controlled study. Intensive Care Medicine, 28(6). http://dx.doi.org/10.1007/s00134-002-1291-9

Rashid, M. S., Sobowale, O., \& Gore, D. (2011). A near-peer teaching program designed, developed and delivered exclusively by recent medical graduates for final year medical students sitting the final objective structured clinical examination (OSCE). BMC Medical Education, 11(11). http://dx.doi.org/10.1186/1472-6920-11-11

Secomb, J. (2008). A systematic review of peer teaching and learning in clinical education. Journal of Clinical Nursing, 17(6), 703-716. http://dx.doi.org/10.1111/j.1365-2702.2007.01954.x

Silbert, B. I., Lam, S. J. P., Henderson, R. D., \& Lake, F. R. (2013). Students as teachers. The Medical Journal of Australia, 199(3), 164-165. http://dx.doi.org/10.5694/mja12.10970

Ten Cate, O., \& Durning, S. (2007a). Dimensions and psychology of peer teaching in medical education. Medical Teacher, 29(6), 546-552. http://dx.doi.org/10.1080/01421590701583816

Ten Cate, O., \& Durning, S. (2007b). Peer teaching in medical education: twelve reasons to move from theory to practice. Medical Teacher, 29(6), 591-599. http://dx.doi.org/10.1080/01421590701606799

Ten Cate, O., van de Vorst, I., \& van den Broek, S. (2012). Academic achievement of students tutored by near-peers. International Journal of Medical Education, 3, 6-13. http://dx.doi.org/10.5116/ijme.4f0c.9ed2

The Council of Ambulance Authorities. (2010). Paramedic Professional Competency Standards V.2 Retrieved from http://www.caa.net.au/downloads/ppcs.pdf

Whitman, N. A. (1988). Peer teaching: to Teach is to Learn Twice ASHE-ERIC Higher Education Report No. 4. Washington, DC: ERIC Clearinghouse on Higher Education.

Williams, B., Fellows, H., Eastwood, K., Wallis, J., \& McKenna, L. (2013 (in press)). Peer teaching experiences of final year paramedic students: 2011-2012. Journal of Peer Learning.

Williams, B., Onsman, A., \& Brown, T. (2009). From stretcher-bearer to paramedic: the Australian paramedics' move towards professionalisation. Journal of Emergency Primary Health Care, 7(4), 1-12.

Williams, B., Onsman, A., \& Brown, T. (2012). A Rasch and Factor Analysis of a Paramedic Graduate Attribute Scale. Evaluation \& the Health Professions, 35(2), 148-168. http://dx.doi.org/10.1177/0163278711407314

Youdas, J. W., Hoffarth, B. L., Kohlwey, S. R., Kramer, C. M., \& Petro, J. L. (2008). Peer Teaching Among Physical Therapy Students During Human Gross Anatomy: Perceptions of Peer Teachers and Students. Anatomical Sciences Education, 1, 199-206. http://dx.doi.org/10.1002/ase.44

Yu, T.-C., Wilson, N. C., Singh, P. P., Lemanu, D. P., Hawken, S. J., \& Hill, A. G. (2011). Medical students-as-teachers: a systematic review of peer-assisted teaching during medical school. Advances in Medical Education and Practice, 2(1), 157-172. http://dx.doi.org/10.2147/AMEP.S14383 